\title{
A Pareto Optimal Solution for Environmental/Economic Power Dispatch using Multi-objective Genetic Algorithm
}

\author{
Jawad Talaq \\ Department of Electrical and Electronics Engineering, \\ University of Bahrain, Bahrain \\ (Received 4 June 2018; accepted 20 September 2018) \\ https://doi.org/10.36224/ijes. 110401
}

\begin{abstract}
The aim of this paper is to apply genetic algorithm (GA) to the solution of the environmental economic power dispatch problem. The environmental economic power dispatch is a multi-objective optimization problem. Fuel cost is considered as one of the objectives. The other objective is emissions such as SO2 or NOx or a combination of both. A trade-off relation between fuel cost and emissions can be formed through a pareto optimal front. Valve point opening and prohibited operating zones add non-smoothness and non-convexities to the objective functions. Evolutionary algorithms can efficiently solve such non-smooth and non-convex problems. Solutions need to be diversified and distributed among the whole range of the pareto optimal front. This allows operators to trade-off between fuel cost and emissions in feasible optimal regions. Applying genetic algorithm with diversity enhancement proves its effectiveness. Application of the algorithm on three and six unit systems is demonstrated.
\end{abstract}

Keywords: Genetic algorithms, Evolutionary programming, Environmental economic power dispatch, Non-convex functions, Non-smooth functions

\section{Introduction}

The environmental economic power dispatch is a multi-objective optimization problem. Fuel cost is considered as one of the objectives. Emissions such as SO2 and NOx are the other objectives. The multi objectives are traditionally combined into a single objective through weighting factors. Many researchers solved the smooth and convex environmental economic power dispatch problem by classical optimization methods based on linear and non-linear programming techniques $[1,2]$. However, prohibited operating zones (POZ) and valve point loading create non-smooth and non-convex objective functions. This causes difficulties in solving the economic power dispatch problem by classical methods. Evolutionary algorithms are efficiently used to solve non-smooth and non-convex environmental economic power dispatch problems. Genetic algorithms (GA) for such problems has been used in [8, 12, 14, 22]. Others used particle swarm optimization (PSO) in [11, 13, 15, 16, 27]. Differential evolution (DE) is used in [17, 21, 26]. Artificial neural networks (ANN) are used in [5, 6]. Fuzzy set theory and interactive fuzzy satisfying methods are used in [3, 24, 26]. Stochastic methods are used in [1, 11]. A surrogate worth trade-off algorithm is used in [4]. Hybrid algorithms are used in [18, 19, 20, 23, 28, 30]. Evolutionary algorithms are used in [7, 9, 10]. A harmony search method is used in [25]. Hony bee mating is used in [24]. Backtracking search optimization is used in [29]. In this paper, a genetic algorithm with diversity enhancement is applied to solve the environmental economic power dispatch problem. The proposed method is applied to power systems of different scales that have been intensively

\footnotetext{
${ }^{*}$ Corresponding author

Email address: jtalaq@gmail.com (Dr. Jawad Talaq)

ISSN 0976 - 6693. (2019 SCMR All rights reserved.
} 
the subject of research in literature. Simulation results are compared with results reported in literature. The results prove that the genetic algorithm based environmental economic dispatch (GAEED) with diversity enhancement technique is comparable with other successful evolutionary techniques to solving the non-smooth and non-convex environmental economic power dispatch problems.

\section{Economic Emissions Power Dispatch}

The economic emissions power dispatch (EEPD) involves the minimization of two objectives subject to equality and inequality constraints.

\subsection{Objectives}

The first objective is the total fuel cost. The fuel cost function is

$$
\begin{aligned}
& C=\sum_{k=1}^{N G} C_{k} \\
& C_{k}=a_{k}+b_{k} P_{k}+c_{k} P_{k}^{2}+\left|e_{k} \sin \left(f_{k}\left(P_{k}-P_{k_{-} \text {min }}\right)\right)\right|
\end{aligned}
$$

The second objective is the total emissions. The emissions function is

$$
\begin{aligned}
& E=\sum_{k=1}^{N G} E_{k} \\
& E_{k}=\alpha_{k}+\beta_{k} P_{k}+\gamma_{k} P_{k}^{2}+\xi_{k} \cdot \exp \left(\lambda_{k} \cdot P_{k}\right)
\end{aligned}
$$

\subsection{Equality constraints}

The equality constraints are simplified to total active power balance equation

$$
\sum_{k=1}^{N G} P_{k}-P_{D}-P_{L}=0
$$

where $\mathrm{P}_{\mathrm{D}}$ is total power demand and $\mathrm{P}_{\mathrm{L}}$ is transmission losses.

$$
P_{L}=\mathrm{P}^{\mathrm{T}} \mathrm{B}_{2} \mathrm{P}+\mathrm{B}_{1} \mathrm{P}+B_{0}
$$

2.3 Inequality constraints

These are minimum and maximum limits on power generation and prohibited operating zones.

$$
\begin{array}{lr}
P_{k_{-} \min } \leq P_{k} \leq P_{k_{-} \max } & k=1,2, \ldots . ., N G \\
P_{k_{-} U_{j}} \leq P_{k} \leq P_{k_{-} L_{j+1}} & j=1, . ., N Z_{k}, k=1, . ., N G
\end{array}
$$

where $L_{j}$ and $U_{j}$ are lower and upper bounds of prohibited operating zone $j$.

\section{Multi-objective Optimization}

Two objectives may be combined through a weighting factor to form a single combined objective as given by (9) that can be optimized easily.

$$
F=\alpha F_{1}+(1-\alpha) F_{2}
$$


A trade-off relation is obtained if the weighting factor is adjusted for the whole range (01) as depicted in Figure 1. This is the pareto-optimal front which dominates all feasible solutions.

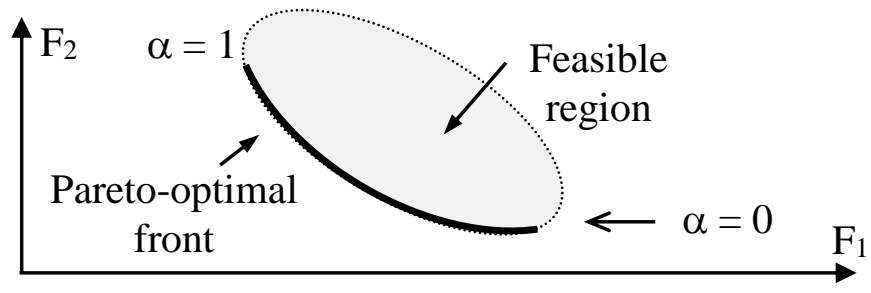

Figure 1: Pareto-optimal front

\section{Genetic Algorithm Based Economic Emissions Power Dispatch}

Genetic algorithms are population based searching techniques. It starts by initializing a population set known as parents. Parents undergo several operations to produce offspring. The process is continued for several generations. The produced offspring become the parents for the next generation. The basic operations are selection, crossover and mutation. Other operations to enhance the quality of the solutions can be included. Members of the population are known as chromosomes. Each chromosome consists of genes representing the variables of the problem. Variables are suitably coded for crossover and mutation. Real coding is implemented in this study. Each chromosome consists of the output power of the generators.

\subsection{Selection}

Population is sorted based on the non-dominance sorting of the objectives. The sorting assigns a class number to each chromosome. The class number represents the number of dominating chromosomes to the specified chromosome. A diversity evaluation to each class is added to the class number to form the fitness function. A population of six chromosomes are shown in Figure 2. The diversity measure is the reciprocal of the distance between the chromosome and its left neighbour. The integer part between the brackets represents the class number while the decimals represent the diversity measure. The population is divided into two groups for crossover.

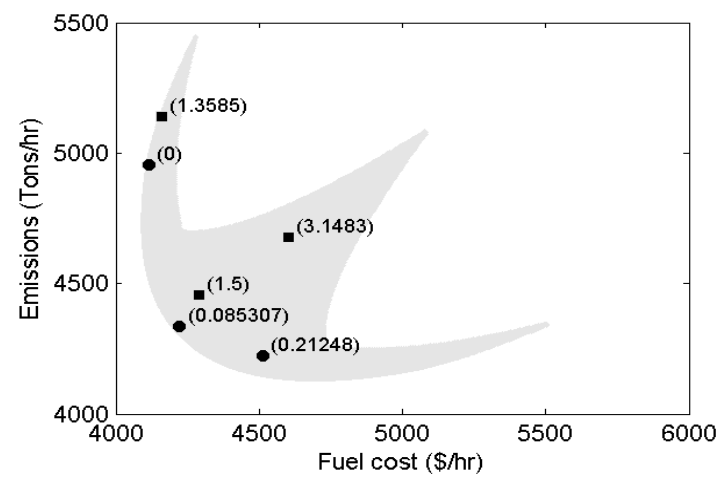

Figure 2: Population sorting

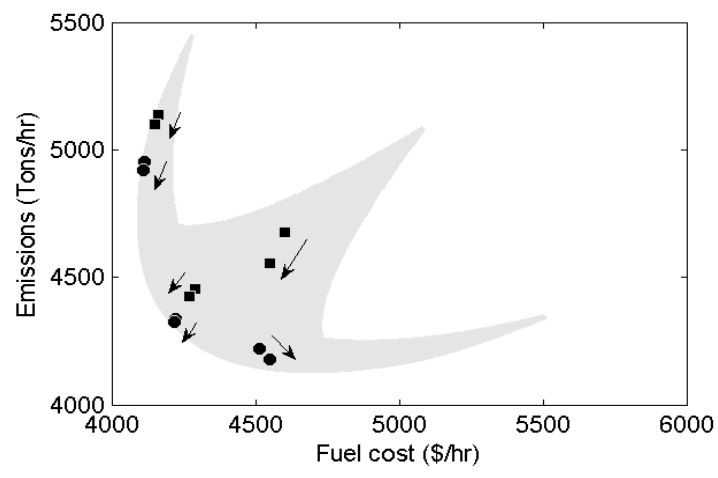

Figure 3: Crossover operation 


\subsection{Crossover}

The crossover operation aims to bring members closer to the pareto-optimal front. Members of the second group are moved closer to the first. Members of the first group are pushed away from the second. Members in the second group are mated with members in the first using (10).

$$
\begin{aligned}
& \text { for each } \mathrm{k} \text { if rand }<p_{\text {cross }}
\end{aligned}
$$

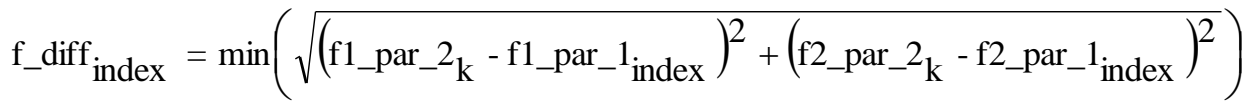

$$
\begin{aligned}
& \mathrm{P} \_ \text {diff }=\mathrm{P}_{\text {}} \text { par_2 } \mathrm{k}-\mathrm{P} \_ \text {par_1 } 1_{\text {index }} \\
& \mathrm{P} \_ \text {par_ } 1_{\text {index }}=\mathrm{P} \_ \text {par_ } 1_{\text {index }}-\mathrm{k}_{\text {cross }} \cdot \mathrm{P} \_ \text {diff } \\
& \text { P_par_2 }=\text { P_par_2 } 2_{\mathrm{k}}-\mathrm{k}_{\text {cross }} \cdot \mathrm{P} \_ \text {diff }
\end{aligned}
$$

where f1_par_1 and f2_par_1 represent the objectives of the first group while f1_par_2 and f2_par_2 represent the objectives of the second group. Selected chromosome genes are adjusted through (12) and (13). $\mathrm{k}_{\text {cross }}$ is a user defined parameter of a positive value less than unity. The crossover operation for the population sorted in Figure 2 is shown in Figure 3.

\subsection{Parents and offspring mating to enhance parents diversity}

Parents diversity is enhanced by selecting the member from the parents with least distance from its neighbour. This member is replaced by a member that can be located between the two members with highest distance between them. The new member location is

$$
\mathrm{P}_{\text {new }}=\mathrm{k}_{1} \cdot \mathrm{P}_{\mathrm{k}}+\mathrm{k}_{2} \cdot \mathrm{P}_{\mathrm{j}}+\mathrm{k}_{3} \cdot \mathrm{P}_{\mathrm{m}}
$$

where $\mathrm{k}_{1}, \mathrm{k}_{2}$ and $\mathrm{k}_{3}$ are weights having the sum of unity.

\subsection{Parents and offspring combination}

Parents and offspring are combined and sorted according to the non-dominance criterion to form a population of twice the original population number. The best $\mathrm{N}_{\text {pop }}$ number of the combination is selected to survive and proceed for mutation.

\subsection{Mutation}

Population members are selected for mutation with a mutation probability. The selected member is mutated using (15) and replaces the member that it most dominates using (16).

$$
\begin{aligned}
& \mathrm{P}_{\text {mut }}=\mathrm{P}_{\mathrm{k}}+\mathrm{k}_{\mathrm{mut}} \cdot(\text { rand }-0.5) \quad \text { if rand }<\mathrm{p}_{\text {mut }} \\
& \text { for all } \mathrm{k} \text { with } \mathrm{f} 1 \_ \text {mut }<\mathrm{f} 1 \_\mathrm{k} \text { and } \mathrm{f} 2 \_ \text {mut }<\mathrm{f} 2 \_\mathrm{k} \mathrm{k}=1: \mathrm{N}_{\text {pop }} \\
& \mathrm{f} \_ \text {diff }{ }_{\mathrm{j}}=\max \left(\sqrt{\left(\mathrm{f} 1 \_\mathrm{mut}-\mathrm{f} 1 \_\mathrm{k}\right)^{2}+\left(\mathrm{f} 2 \_ \text {mut }-\mathrm{f} 2 \_\mathrm{k}\right)^{2}}\right) \\
& \mathrm{P}_{\mathrm{j}} \Leftarrow \mathrm{P}_{\mathrm{mut}}
\end{aligned}
$$

\subsection{Pareto-optimal front boundaries modification}

The pareto-optimal front extremes contain two members. One has least fuel cost and highest emissions. The other has highest cost and least emissions. Both are improved as follows 


$$
\begin{aligned}
& \mathrm{P}_{\text {temp1 }}=\mathrm{P}_{\mathrm{k} 1}+\mathrm{k}_{\mathrm{b}} \cdot \text { rand } \cdot\left(\mathrm{P}_{\mathrm{k} 1}-\mathrm{P}_{\mathrm{n} 1}\right) \text { and } \quad \mathrm{P}_{\text {temp2 }}=\mathrm{P}_{\mathrm{k} 2}+\mathrm{k}_{\mathrm{b}} \cdot \operatorname{rand} \cdot\left(\mathrm{P}_{\mathrm{k} 2}-\mathrm{P}_{\mathrm{n} 2}\right) \\
& \mathrm{P}_{\mathrm{k} 1} \Leftarrow \mathrm{P}_{\text {temp1 }} \quad \text { if } \mathrm{f}_{1}\left(\mathrm{P}_{\text {temp1 } 1}\right) \geq \mathrm{f}_{1}\left(\mathrm{P}_{\mathrm{k} 1}\right) \text { and } \mathrm{f}_{2}\left(\mathrm{P}_{\text {temp1 } 1}\right) \leq \mathrm{f}_{2}\left(\mathrm{P}_{\mathrm{k} 1}\right) \\
& \mathrm{P}_{\mathrm{k} 2} \Leftarrow \mathrm{P}_{\text {temp2 }} \text { if } \mathrm{f}_{1}\left(\mathrm{P}_{\text {temp2 } 2}\right) \leq \mathrm{f}_{1}\left(\mathrm{P}_{\mathrm{k} 2}\right) \text { and } \mathrm{f}_{2}\left(\mathrm{P}_{\text {temp2 } 2}\right) \geq \mathrm{f}_{2}\left(\mathrm{P}_{\mathrm{k} 2}\right)
\end{aligned}
$$

where $\mathrm{k} 1$ represents the member of highest fuel cost and least emissions while $\mathrm{k} 2$ is the member of least fuel cost and highest emissions. Members $\mathrm{n} 1$ and $\mathrm{n} 2$ are the closest members.

\subsection{Diversity Enhancement}

Diversity enhancement is activated at the end of mutation. Each member is moved to the centre between its neighbours by replacing its variables by the mean of both as in (20).

$$
P_{k}=0.5\left(P_{n 1}+P_{n 2}\right)
$$

\subsection{Feasibility satisfaction}

The power mismatch is determined when chromosomes are changed due to GA operations. Chromosomes are iteratively adjusted to satisfy the power balance using (21) and (22).

$$
\begin{aligned}
& \Delta P_{k}=\sum_{j=1}^{N G} P_{j k}-P_{D}-P_{L} \\
& \mathrm{P}_{k}=\mathrm{P}_{k}-\Delta P_{k} / N G
\end{aligned}
$$

where $\Delta P_{\mathrm{k}}$ is the power mismatch of chromosome $\mathrm{k}$ and $P_{\mathrm{jk}}$ are elements of vector $\mathrm{P}_{\mathrm{k}}$ representing the output power of generators. $P_{L}$ denotes the transmission losses defined by (6).

\section{Simulation}

The algorithm has been tested on two different systems. These systems consist of 3 and 6 units which have been the subject of intensive research in literature. The number of population used is 100 for all simulations. The crossover and mutation probabilities are set to 0.80 and 0.20 respectively.

\subsection{3-Units system}

Fuel cost and emission parameters together with generation limits and prohibited zones are shown in Tables 1 and 2. Demand is 850.0 MW. Losses B-coefficients are in [10]. Two cases have been studied. One neglects prohibited zones (POZ) while the other includes them. Results are shown in Table 3 and Figure 4-7.

\subsection{6-Units system}

Fuel cost and emission parameters together with generation limits and prohibited zones are shown in Tables 4 and 5. Demand is 2.834pu (100MVA base). Losses B-coefficients are in [18]. Two cases have been studied. One neglects prohibited zones (POZ) while the other includes them. Results are shown in Table 6 and Figure 8-9. 
Table 1: Three units cost parameters and operating limits

Fuel cost parameters Generation limits POZ limits

\begin{tabular}{|c|c|c|c|c|c|c|c|c|c|}
\hline Unit & $\mathrm{a}(\$ / \mathrm{hr})$ & $\mathrm{b}(\$ / \mathrm{MW} / \mathrm{hr})$ & $\mathrm{c}\left(\$ / \mathrm{MW}^{2} / \mathrm{hr}\right)$ & $\mathrm{e}(\$ / \mathrm{hr})$ & $\mathrm{f}(1 / \mathrm{MW})$ & $\operatorname{Pmin}(\mathrm{MW})$ & $\operatorname{Pmax}(\mathrm{MW}$ & POZ1(MW) & POZ2(MW) \\
\hline 1 & 561.0 & 7.9200 & 0.001562 & 200.0 & 0.0180 & 150.0 & 600.0 & {$\left[\begin{array}{ll}200 & 210\end{array}\right]$} & {$\left[\begin{array}{ll}510 & 520\end{array}\right]$} \\
\hline 2 & 310.0 & 7.8500 & 0.001940 & 200.0 & 0.0220 & 100.0 & 400.0 & {$\left[\begin{array}{ll}180 & 190\end{array}\right]$} & {$\left[\begin{array}{ll}280 & 290\end{array}\right]$} \\
\hline 3 & 78.0 & 7.9700 & 0.004820 & 60.0 & 0.0460 & 50.0 & 200.0 & {$\left[\begin{array}{ll}60 & 70\end{array}\right]$} & {$\left[\begin{array}{ll}85 & 95\end{array}\right]$} \\
\hline
\end{tabular}

Table 2: Three units emission parameters

$\mathrm{SO} 2$ emission parameters

NOx emission parameters

\begin{tabular}{ccccccc}
\hline Unit & $\alpha(\mathrm{Ton} / \mathrm{hr})$ & $\beta($ Ton $/ \mathrm{MW} / \mathrm{hr})$ & $\gamma\left(\mathrm{Ton} / \mathrm{MW}^{2} / \mathrm{hr}\right)$ & $\alpha(\mathrm{Ton} / \mathrm{hr})$ & $\beta(\mathrm{Ton} / \mathrm{MW} / \mathrm{hr})$ & $\gamma\left(\mathrm{Ton} / \mathrm{MW}^{2} / \mathrm{hr}\right)$ \\
\hline 1 & 0.5783298 & $8.16466 \mathrm{e}-3$ & $1.6103 \mathrm{e}-6$ & 0.043732540 & $-9.4868099 \mathrm{e}-5$ & $1.4721848 \mathrm{e}-7$ \\
2 & 0.3515338 & $8.91174 \mathrm{e}-3$ & $2.1999 \mathrm{e}-6$ & 0.055821713 & $-9.7252878 \mathrm{e}-5$ & $3.0207577 \mathrm{e}-7$ \\
3 & 0.0884504 & $9.03782 \mathrm{e}-3$ & $5.4658 \mathrm{e}-6$ & 0.027731524 & $-3.5373734 \mathrm{e}-4$ & $1.9338531 \mathrm{e}-6$ \\
\hline
\end{tabular}

Table 3: Three units solution with valve point loading and prohibited operating zones

\begin{tabular}{ccccccc}
\hline & \multicolumn{2}{c}{ Minimum fuel cost } & \multicolumn{2}{c}{ Minimum SO2 emissions } & \multicolumn{2}{c}{ Minimum NOx emissions } \\
\hline Method & VPL & VPL and POZ & VPL & VPL and POZ & VPL & VPL and POZ \\
P1 (MW) & $\mathbf{5 1 2 . 3 2 5 2 6 2}$ & 520.000000 & 552.684014 & 522.522383 & 508.686446 & 508.894654 \\
P2 (MW) & $\mathbf{2 8 5 . 5 9 9 2 2 5}$ & 275.532730 & 219.151506 & 247.253678 & 250.326563 & 250.140565 \\
P3 (MW) & $\mathbf{6 7 . 8 4 3 1 7 4}$ & 70.000000 & $\underline{92.681444}$ & 95.000000 & 105.731044 & 105.706176 \\
Ploss (MW) & 15.767661 & 15.532730 & 14.516964 & 14.776061 & 14.744054 & 14.741396 \\
Fuel cost (\$/hr) & 8421.249722 & 8443.074225 & 8749.826861 & 8583.843045 & 8617.616010 & 8617.601894 \\
SO2 (Tons/hr) & 8.986879 & 8.981281 & 8.965938 & 8.970063 & 8.983458 & 8.973555 \\
Nox (Tons/hr) & 0.099062 & 0.098613 & 0.128420 & 0.096179 & 0.095924 & 0.095924 \\
\hline
\end{tabular}

Table 4: Six units cost parameters and limits

Fuel cost parameters $\quad$ Generation limits POZ limits

\begin{tabular}{|c|c|c|c|c|c|c|c|c|c|}
\hline Unit & $\mathrm{a}(\$ / \mathrm{hr})$ & $\mathrm{b}(\$ / \mathrm{MW} / \mathrm{hr})$ & $\mathrm{c}\left(\$ / \mathrm{MW}^{2} / \mathrm{hr}\right)$ & $\mathrm{e}(\$ / \mathrm{hr})$ & $\mathrm{f}(1 / \mathrm{MW})$ & $\operatorname{Pmin}(\mathrm{pu})$ & $\operatorname{Pmax}(\mathrm{pu})$ & POZ1(pu) & POZ2(pu) \\
\hline 1 & 10 & 200 & 100 & 15 & 6.283 & 0.0500 & 0.5000 & {$\left[\begin{array}{ll}0.10 & 0.20\end{array}\right]$} & {$\left[\begin{array}{ll}0.30 & 0.40\end{array}\right]$} \\
\hline 2 & 10 & 150 & 120 & 10 & 8.976 & 0.0500 & 0.6000 & {$\left[\begin{array}{ll}0.10 & 0.20\end{array}\right]$} & {$\left[\begin{array}{ll}0.30 & 0.40\end{array}\right]$} \\
\hline 3 & 20 & 180 & 40 & 10 & 14.784 & 0.0500 & 1.0000 & {$\left[\begin{array}{ll}0.20 & 0.30\end{array}\right]$} & {$\left[\begin{array}{ll}0.80 & 0.90\end{array}\right]$} \\
\hline 4 & 10 & 100 & 60 & 5 & 20.944 & 0.0500 & 1.2000 & {$\left[\begin{array}{ll}0.20 & 0.30\end{array}\right]$} & {$\left[\begin{array}{ll}0.80 & 0.90\end{array}\right]$} \\
\hline 5 & 20 & 180 & 40 & 5 & 25.133 & 0.0500 & 1.0000 & {$\left[\begin{array}{ll}0.20 & 0.30\end{array}\right]$} & {$\left[\begin{array}{ll}0.50 & 0.60\end{array}\right]$} \\
\hline 6 & 10 & 150 & 100 & 5 & 18.480 & 0.0500 & 0.6000 & {$\left[\begin{array}{ll}0.10 & 0.20\end{array}\right]$} & {$\left[\begin{array}{ll}0.30 & 0.40\end{array}\right]$} \\
\hline
\end{tabular}

Table 5: Six units NOx emission parameters

\begin{tabular}{cccccc}
\hline Unit & $\alpha(\mathrm{Ton} / \mathrm{hr})$ & $\beta(\mathrm{Ton} / \mathrm{MW} / \mathrm{hr})$ & $\gamma\left(\mathrm{Ton} / \mathrm{MW}^{2} / \mathrm{hr}\right)$ & $\zeta(\mathrm{Ton} / \mathrm{hr})$ & $\lambda(1 / \mathrm{MW})$ \\
\hline 1 & 0.04091 & -0.05554 & 0.06490 & $2.0 \mathrm{e}-4$ & 2.857 \\
2 & 0.02543 & -0.06047 & 0.05638 & $5.0 \mathrm{e}-4$ & 3.333 \\
3 & 0.04258 & -0.05094 & 0.04586 & $1.0 \mathrm{e}-6$ & 8.000 \\
4 & 0.05326 & -0.03550 & 0.03380 & $2.0 \mathrm{e}-3$ & 2.000 \\
5 & 0.04258 & -0.05094 & 0.04586 & $1.0 \mathrm{e}-6$ & 8.000 \\
6 & 0.06131 & -0.05555 & 0.05151 & $1.0 \mathrm{e}-5$ & 6.667 \\
\hline
\end{tabular}

Table 6: Six units solution with valve point loading and prohibited operating zones

\begin{tabular}{ccccc}
\hline & \multicolumn{2}{c}{ Minimum fuel cost } & \multicolumn{2}{c}{ Minimum NOx emissions } \\
\hline Method & VPL & VPL and POZ & VPL & VPL and POZ \\
P1 (pu) & 0.050002 & 0.050000 & 0.410788 & 0.098948 \\
P2 (pu) & $\underline{\mathbf{0 . 3 9 5 7 1 7}}$ & 0.400000 & 0.463542 & 0.419641 \\
P3 (pu) & 0.687492 & 0.686254 & 0.544392 & 0.683814 \\
P4(pu) & $\mathbf{0 . 8 0 0 0 4 2}$ & 0.900000 & 0.390354 & 0.600543 \\
P5 (pu) & $\underline{\mathbf{0 . 5 5 0 0 4 6}}$ & 0.421241 & $\underline{\mathbf{0 . 5 4 4 4 1 2}}$ & 0.633717 \\
P6 (pu) & $\underline{\mathbf{0 . 3 7 2 8 9 0}}$ & 0.400000 & 0.515371 & 0.418566 \\
Ploss (pu) & 0.022189 & 0.023495 & 0.034859 & 0.021233 \\
Fuel cost $(\$ / \mathrm{hr})$ & 612.3612 & 615.2387 & 679.6607 & 636.7332 \\
Nox (Tons/hr) & 0.212999 & 0.217699 & 0.194178 & 0.204650 \\
\hline
\end{tabular}




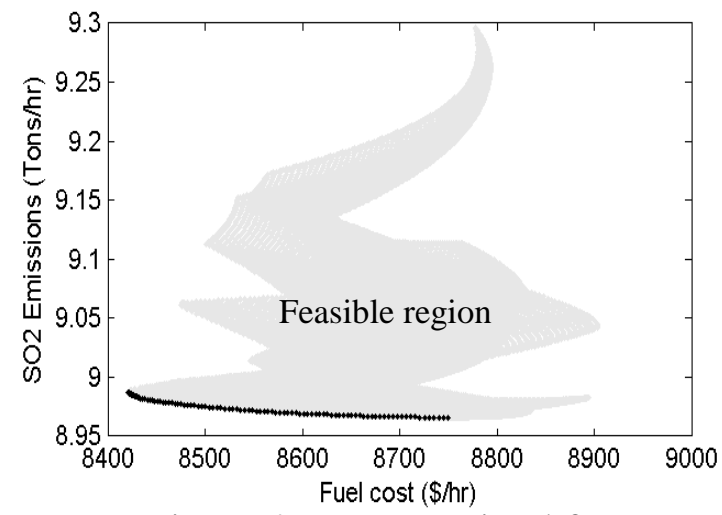

Figure 4: Pareto optimal front without POZ Minimizing fuel cost

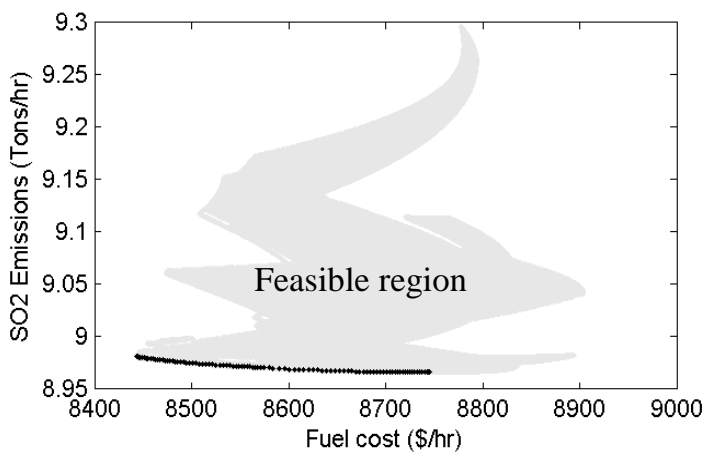

Figure 6: Pareto optimal front with POZ Minimizing fuel cost and $\mathrm{CO} 2$

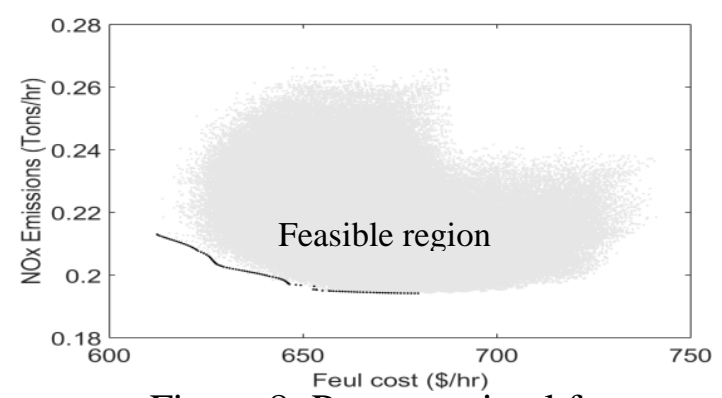

Figure 8: Pareto optimal front without POZ Minimizing fuel cost

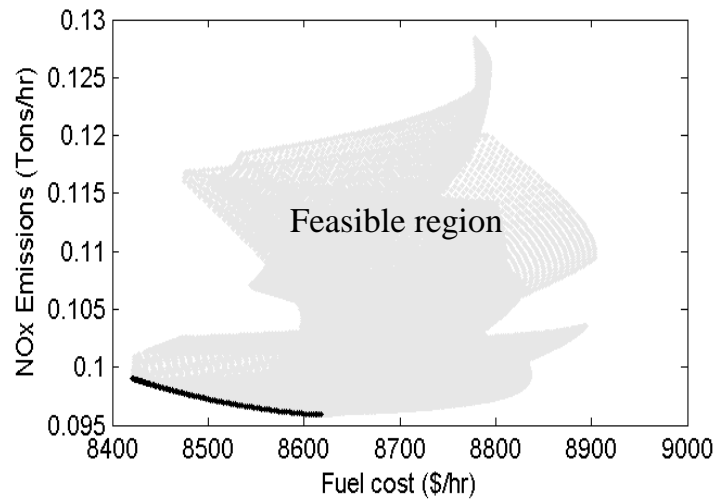

Figure 5: Pareto optimal front without POZ Minimizing fuel cost

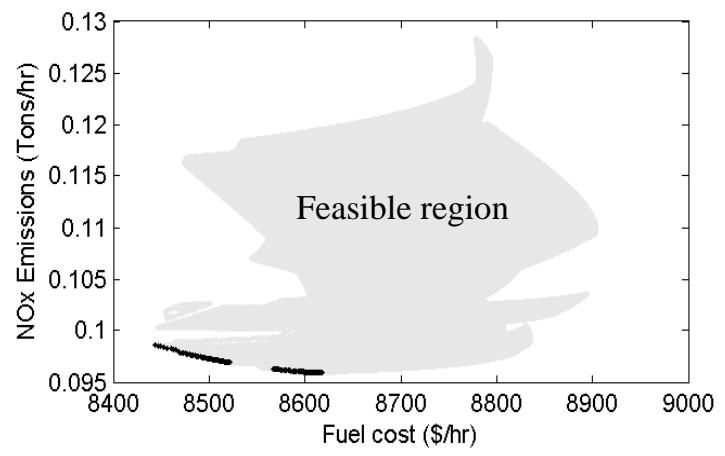

Figure 7: Pareto optimal front with

POZ Minimizing fuel cost and NOx

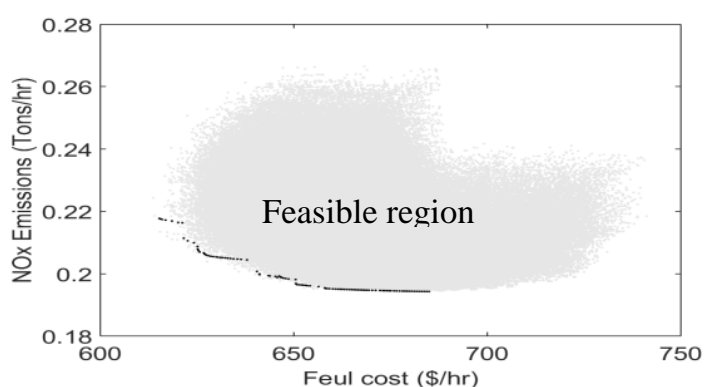

Figure 9: Pareto optimal front with POZ Minimizing fuel cost and NOx

\section{Conclusions}

A genetic algorithm based environmental economic power dispatch with diversity enhancement (GAEED) is proposed in this paper. A genetic algorithm is an evolutionary algorithm that relies on mating between chromosomes to produce offspring. The operations of a genetic algorithm are selection, crossover and mutation. In this paper, a genetic algorithm is used to solve the multi-objective optimisation of the environmental economic power dispatch problem. Population of the genetic algorithm evolve to discover the pareto optimal front of the feasible solutions. The problem is non-smooth and non-convex due to 
prohibited operating zones and valve point opening. A diversity enhancement aiming to diversify the solutions among the pareto optimal front to cover the whole front is proposed. The proposed algorithm has been simulated on three and six unit systems with transmission losses and non-smooth objective functions.

\section{References}

[1] Dhillon JS, Parti C, Kothari DP., Stochastic economic emission load dispatch, Electr Power Syst Res 1993, 26, 179-186

[2] Dhillon JS, Parti SC, Kothari DP., Multiobjective optimal thermal power dispatch, Int J Electr Power Energy Syst 1994, 16 (6), 383-389

[3] Hota P, Chakrabarti R, Chattopadhyay P. Economic emission load dispatch through an interactive fuzzy satisfying method. Electr Power Syst Res 2000, 54, 151-157

[4] Dhillon JS, Kothari DP. The surrogate worth trade-off approach for multiobjective thermal power dispatch problem. Electr Power Syst Res 2000, 56, 103-110

[5] Basu M. Fuel constrained economic emission load dispatch using hopfield neural networks, Electr Power Syst Res 2002, 2, 63, 51- 57

[6] Balakrishnan S, Kannan PS, Aravindan C, Subathra P., On-line emission and economic load dispatch using adaptive Hopfield neural network, Applied Soft Computing 2003, 2, 297-305

[7] Abido MA. A novel multiobjective evolutionary algorithm for environmental/economic power dispatch, Electr Power Syst Res 2003, 65, 71-81

[8] Abido MA. A niched Pareto genetic algorithm for multiobjective environmental/ economic dispatch, Int J Electr Power Energy Syst 2003, 25, 97-105

[9] Abido MA. Environmental/Economic Power Dispatch Using Multiobjective Evolutionary Algorithms. IEEE Trans power syst 2003, 18, 4, 1529-1537

[10] AhKing RTF, Rughooputh HCS., Elitist multi-objective evolutionary algorithm for environmental/economic dispatch., Cong Evolutionary Comp, 2003, 2, 1108-1114

[11] Lingfeng W, Chanan S., Stochastic economic emission load dispatch through a modified particle swarm optimization algorithm. Electr Power Syst Res 2008, 78, 1466-1476

[12] Basu M., Dynamic economic emission dispatch using nondominated sorting genetic algorithm-II. Int J Electr Power Energy Syst 2008, 30, 140-149

[13] S. Hemamalini, S., and Sishaj P Simon, Emission Constrained Economic Dispatch with Valve-Point Effect using Particle Swarm Optimization, TENCON 2008 - 2008 IEEE Region 10 Conference, 19-21 Nov. 2008

[14] Osmana MS, Abo-Sinnab MA, Mousab AA. An ع-dominance-based multiobjective genetic algorithm for economic emission load dispatch optimization problem, Electr Power Syst Res 2009, 79, 1561-1567

[15] Abido MA., Multiobjective particle swarm optimization for environmental/economic dispatch problem., Electr Power Syst Res 2009, 79, 1105-1113

[16] Jiejin Cai, Xiaoqian Ma, Qiong Li, Lixiang Li, Haipeng Peng., A multi-objective chaotic particle swarm optimization for environmental/economic dispatch. Energy Conversion and Management 2009, 50, 1318-1325

[17] Wu LH, Wang YN, Yuan XF, Zhou SW., Environmental/economic power dispatch problem using multi-objective differential evolution algorithm. Electr Power Syst Res 2010, 80, 11711181

[18] Dun-wei Gong, Yong Zhang, Cheng-liang Qi., Environmental/economic power dispatch using a hybrid multi-objective optimization algorithm. Int J Electr Power Energy Syst 2010, 32, 607-614

[19] Aniruddha B, Pranab KC., Solving economic emission load dispatch problems using hybrid differential evolution. Applied Soft Computing 2011, 11, 2526-2537 
[20] Aniruddha B, Chattopadhyay PK., Hybrid differential evolution with biogeography-based optimization algorithm for solution of economic emission load dispatch problems., Expert Systems with Applications 2011, 38, 14001-14010

[21] Lu Y, Zhou J, Qin H, Wang Y, Zhang Y., Environmental/economic dispatch problem of power system by using an enhanced multi-objective differential evolution algorithm. Energy Conversion and Management 2011, 52, 1175-1183

[22] Celal Y, Serdar O. Solution to scalarized environmental economic power dispatch problem by using genetic algorithm., Int J Electr Power Energy Syst 2012, 38, 54-62

[23] Rahmat-Allah H, Moein P, Mohammad JM., Emission, reserve and economic load dispatch problem with non-smooth and non-convex cost functions using the hybrid bacterial foragingNelder-Mead algorithm., Applied Energy 2012, 89, 443-453

[24] Ali Ghasemi., A fuzzified multi objective Interactive Honey Bee Mating Optimization for Environmental/Economic Power Dispatch with valve point effect., Int J Electr Power Energy Syst 2013, 49, 308-321

[25] Babak J, Vahid V., A modified harmony search method for environmental/economic load dispatch of real-world power systems. Energy Conversion and Management 2014, 78, 661675

[26] Manjaree P, Laxmi S, Manisha S., Environmental economic dispatch in multi-area power system employing improved differential evolution with fuzzy selection. Applied Soft Computing, 2015, 28, 498-510

[27] Vinay K J, Nikhil G, Niazi K R, Anil S., Modulated particle swarm optimization for economic emission dispatch, Int J Electr Power Energy Syst, 2015, 73, 80-88

[28] Radosavljević J., A Solution to the Combined Economic and Emission Dispatch Using Hybrid PSOGSA Algorithm, Appl Artificial Intellig, 2016, 30, 5, 445-474

[29] Chaib AE, Bouchekara HREH, Mehasni R, Abido MA., Optimal power flow with emission and non-smooth cost functions using backtracking search optimization algorithm, Int $\mathrm{J}$ Electr Power Energy Syst., 2016, 81, 64-77

[30] Neto JXV, Reynoso-Meza G, Ruppel TH, Mariani VC, Coelho LDS, Solving non-smooth economic dispatch by a new combination of continuous GRASP algorithm and differential evolution, Int J Electr Power Energy Syst, 2017, 84, 13 - 24

Jawad Talaq, received B.Sc. in Electrical Engineering from the University of Technology at Baghdad in 1981, M.Sc. in Power Engineering from the University of Strathclyde in 1987, and Ph.D. in Electrical Engineering from the Technical University of Nova Scotia (DalTech) in 1993. Between 1981 and 1989, he was with the Electricity Directorate of Bahrain. Since 1989, he has been on Faculty in the Department of Electrical and Electronics Engineering at the University of Bahrain where he is Associate Professor. 